\title{
PERMEABILITY OF SINTER BRONZE FRICTION MATERIAL FOR WET CLUTCHES
}

\author{
Pär Marklund, Roland Larsson \\ Div. of Machine Elements \\ Dept. of Applied Physics and Mechanical Engineering \\ Luleå University of Technology \\ Luleå, SE-97187, Sweden
}

\author{
T. Staffan Lundström \\ Div. of Fluid Mechanics \\ Dept. of Applied Physics and Mechanical Engineering \\ Luleå University of Technology \\ Luleå, SE-97187, Sweden
}

\begin{abstract}
The characteristics of wet clutches are of great importance for the overall behavior of the drive trains of many modern vehicles. It is considered that the clutch characteristic is affected by the permeability of the friction material. The permeability is considered to influence both the time of engagement and the temperature in the clutch due to the lubricant flow in the permeable material. In this work, a permeability measurement method suitable for wet clutch friction materials is thus used to measure the permeability of a friction material made of sintered bronze. This friction material is suitable for applications such as limited slip differentials or other wet clutches which have to withstand high temperature and high torque transfer. The permeability is also investigated for friction materials with pressed groove patterns.

Wet clutch friction material permeability is often accounted for in simulations but the method used to measure the permeability is seldom described.

The permeability of the investigated friction material is shown to be so small that it hardly will affect the temperature in the material due to cooling oil flow inside the material. However, the engagement time could be affected by the permeability. It was also shown that pressed groove patterns can seal the friction material so that it becomes almost impermeable.
\end{abstract}

\section{INTRODUCTION}

Wet clutches are often used in modern vehicles to distribute torque in transmissions and drive trains. The characteristics of these clutches are of great importance for the overall behavior of the vehicle. There are many properties of the clutch affecting the friction characteristics, such as materials, lubricants, surface roughness and permeability of the friction material. The permeability, i.e. the possibility to a fluid flow inside the friction material, is considered to decrease the time of engagement and to allow a cooling flow in the friction material. The time of engagement could be decreased due to smaller squeeze film effects on the contact areas of the friction discs and internal temperature could be decreased due to fluid flow in the material.
The permeability is one of the input parameters in many simulation models developed for wet clutches [1-4]. However, the method used to obtain the permeability for the friction material is normally not thoroughly described. The value of permeability is also widely varied between roughly $1 \cdot 10^{-15}$ and $1 \cdot 10^{-11} \mathrm{~m}^{2}$ in the simulation models. The effects of the permeability are often not studied but in some work, e.g. [3] the permeability is varied and the influence on, for example, torque transfer during clutch engagement is investigated. However, it is not investigated how groove patterns in the friction material can influence the permeability.

Measurements of permeability range all way back to 1856 when Darcy did his experiments on sand [5]. During the latest decades much effort has been spend on methods to measure the permeability of materials having a sheet like form in connection to composites manufacturing [6-8] and making of paper [9]. For wet clutch friction materials little has been done so far. Chavdar's investigation [10] on paper based friction materials is one example of a permeability measurement made especially for wet clutch friction materials. However for thin layers of sintered friction materials there is not much work done. To get a better idea of the permeability of friction material from sintered bronze this investigation is made. It is also investigated how the permeability changes due to density of the porous friction material and groove patterns. The sintered bronze friction material investigated here is similar to the material investigated by Beavers [11] for a naturally permeable wall but the layer is much thinner. This material is used in heavy duty wet clutches which are working under limited slip conditions, i.e. limited slip during a long time with high surface pressures and torque transfer. An example of a friction disc with this friction material is shown in Fig. 1. The grooves visible in Fig. 1 are pressed in the friction material to make a larger cool flow possible between the friction discs even when the clutch is working under boundary lubrication condition, i.e. surfaces in contact with each other.

The permeability investigations are made in a test rig [6] originally designed to measure permeability in different textile 


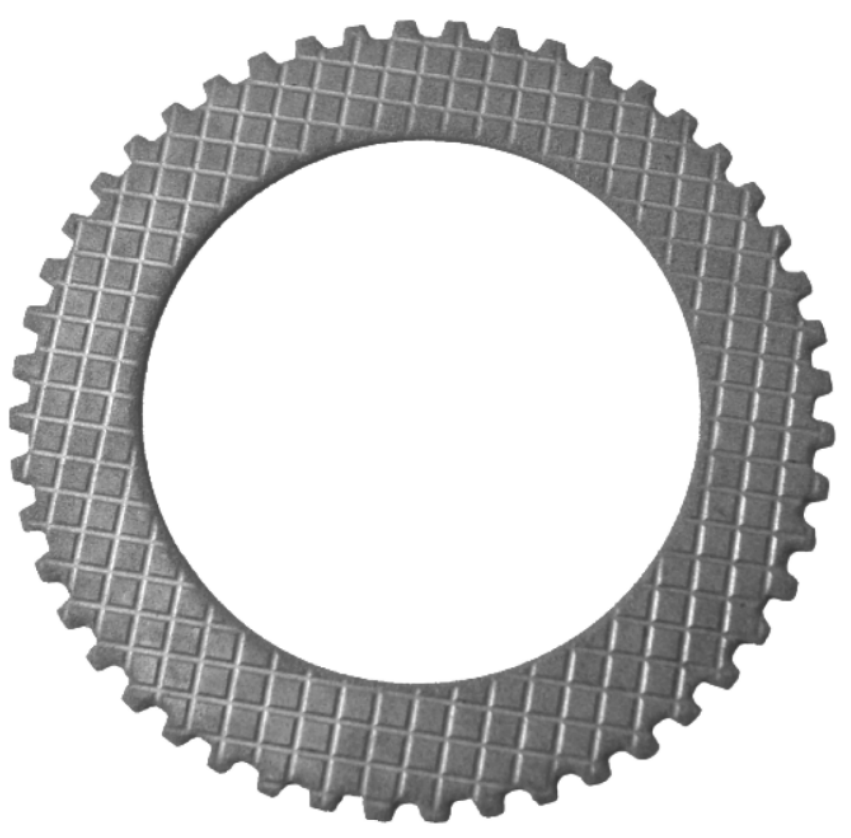

Figure 1. Friction disc with grooves. Friction material of sintered bronze.

materials such as press fabric used in paper machines. Different densities, hence porosity, of the friction material is investigated to see how this influences the permeability.

The groove pattern on the friction disc in Fig. 1 is pressed after the sinter process of the friction material. Because of this way of manufacture the friction discs there is a possibility that the groove walls will be so dense that the fluid flow into the material will be prevented. This is why the investigation of the permeability of the friction material is extended to include also an investigation of how transversal grooves will influence the permeability.

\section{METHOD}

The flow through the material in one direction is measured by the use of an experimental method described by Lundström et.al. [6]. In the wet clutch application, where the friction material is used, the permeability property is supposed to cool down the friction disc as well as reduce the time of engagement. The permeability value depends on the internal structure of the material as well as the porosity. Since special test specimens have to be manufactured for the tests, see Fig. 3, it is important that the friction material used in the investigation is manufactured in the same way as the original friction discs, see Fig. 1.

\subsection{Test rig}

The test rig used is originally developed for permeability investigations of textile materials such as press fabric used in paper machines and fiber mats for different composites [6]. The rig is constructed so that different test cells can be used depending on the investigated material. Such a cell can, for instance, be designed for parallel flow measurements in plane or out of plane. In these measurements the in-plane parallel flow cell is used to measure the permeability in rectangular shaped specimens.
The test cell, see Fig. 2, is designed as a holder for rectangular test specimens with a thickness between 1 and $5 \mathrm{~mm}$ and is sealed at the edges perpendicular to the flow. On top of the test specimen a closing cap is placed to prevent any flow to pass over the specimen instead of going through the permeable material. The specimen is also sealed between the cap and the test cell with a rubber layer to make sure that all flow passes through the material.

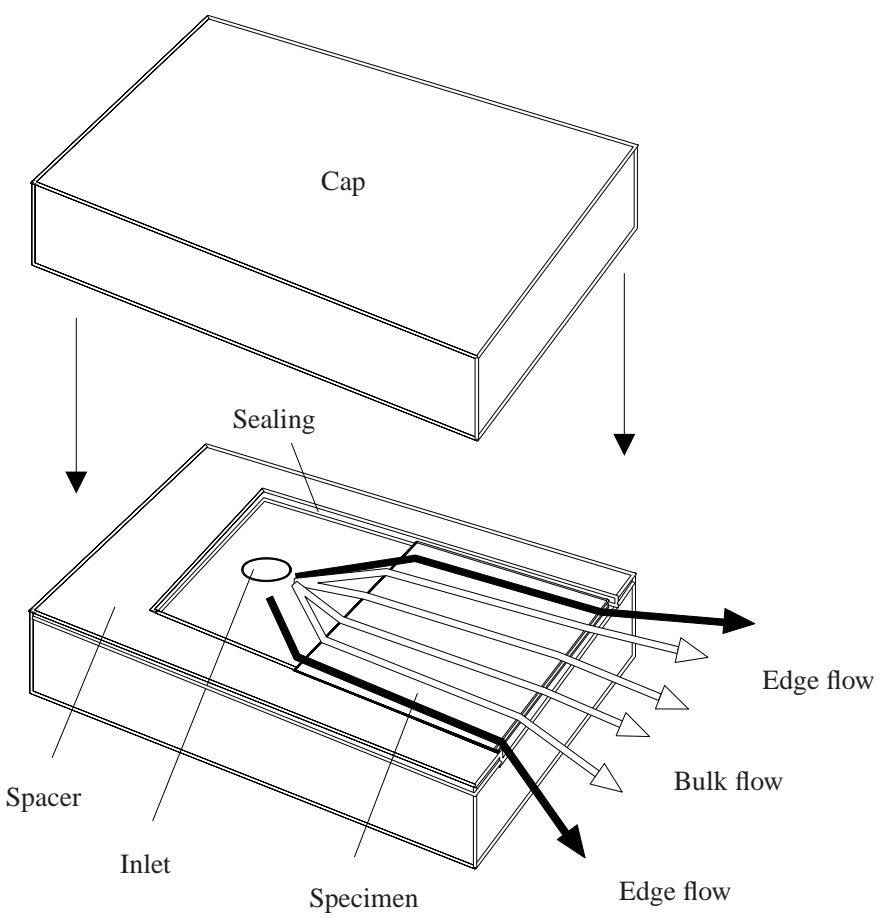

Figure 2. Test cell for parallel flow

One difficulty of this method is to obtain a precise fit between the test cell and the specimen. A specimen misfit can result in leakage or suppressed flow along the sides of the sample which will influence the permeability values. Therefore the center bulk flow is separated from the edge flow so that possible leakage can be measured separately and will not influence the bulk flow measurement. The presented flow and permeability values are the values from measurements of the center bulk flow covering the middle $70 \%$ of the specimen width.

The pressure gradient through the test specimen is considered to be linear between the measured inlet pressure, $p_{\text {inlet }}$, and the ambient pressure, $p_{a m b}$. The pressure transducer (WIKA type 891.13.500) is placed next to the inlet hole, see Fig. 2, while the temperature is measured at the inlet with a thermometer (GEFRAM PT100) to be able to calculate the density and the viscosity of the fluid that is flowing through the permeable material. The mass of the fluid that is transported through the permeable test specimen is then measured with two separate balances (Precisa 3100D), one for the bulk flow and one for the edge flow both with a precision of 0.1 gram. 


\subsection{Test specimens}

The test specimens are made of a rectangular steel backing plate which is covered with powder of bronze that forms the friction material layer, see Fig. 3 and the cross sections in Fig. 7. The friction material is sintered to a porous structure and then the surface is flattened. This is the same manufacturing process as normally used for manufacturing friction discs with friction material of sintered bronze. However, the specimens used in this measurement only have friction material attached on one side in contrary to most of the friction discs used in wet clutches. Since the significance of the friction material density is of interest, test specimens with three different densities of friction material are investigated. The different densities give variations in porosities which are roughly estimated in Table 1 .

The dimensions of the test specimens are shown in Table 2.

Table 1. Estimates of porosity for friction material with different density.

\begin{tabular}{|c|c|}
\hline Density & Porosity [\%] \\
\hline Normal & 57 \\
\hline High & 55 \\
\hline Low & 61 \\
\hline
\end{tabular}

Table 2. Dimensions of test specimens.

\begin{tabular}{|c|c|c|}
\hline & Type 1 & Type 2 \\
\hline Size $[\mathrm{mm}]$ & $30 \times 100$ & $45 \times 100$ \\
\hline Steel thickness $[\mathrm{mm}]$ & 1.0 & 1.0 \\
\hline Friction material thickness [mm] & 0.6 & 0.6 \\
\hline
\end{tabular}

Since most of the friction discs used in wet clutches have some kind of a groove pattern it is of interest to see how the grooves are influencing the over all permeability of the friction material. Test specimens with and without pressed grooves are investigated, see Fig 3. The groove pattern in Fig. 3(a) consists of pressed grooves with a depth of $0.3 \mathrm{~mm}$ and a with of $1.5 \mathrm{~mm}$, according to Fig. 4. The spacing between the grooves is $6 \mathrm{~mm}$.

\subsection{Friction material analysis}

A Scanning Electron Microscope (SEM) is used to investigate the surface of the friction material. The investigated specimen has a friction material with a normal density according to Table 1. Figure 5 shows a larger area of the surface and the porous structure of the friction material is clearly seen. The few contact areas are also easy to locate on the very rough surface. This structure gives large connected pores in the surface interface layer when the friction material is in contact with the quite smooth steel counter surface like the steel separator discs in the clutch.

Figure 6 shows the same surface with a higher magnifica-

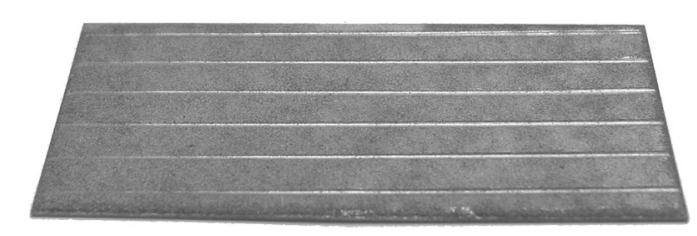

(a) Groove pattern orthogonal to the flow direction

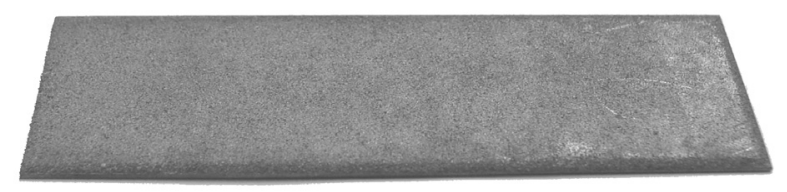

(b) Without groove pattern

Figure 3. Examples of test specimens used for the permeability measurements.

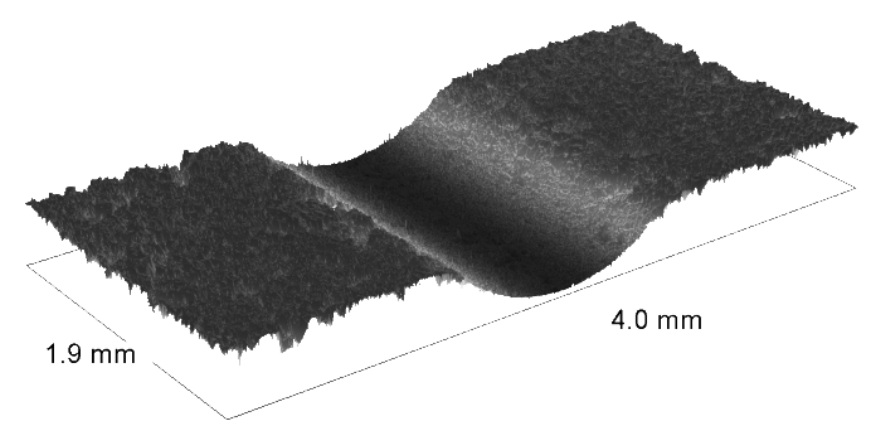

Figure 4. Topographic picture of pressed groove.

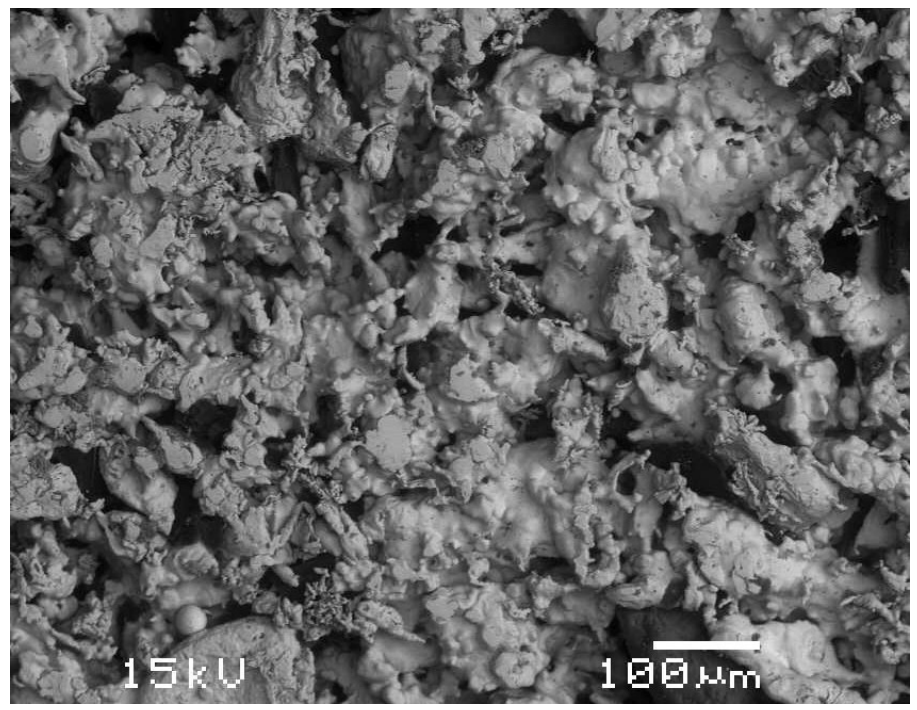

Figure 5. SEM picture of friction material surface. Magnification 100x.

tion. This shows the structure of the powder that is used in the friction material.

To see how dense the friction material is at the grooves, a 


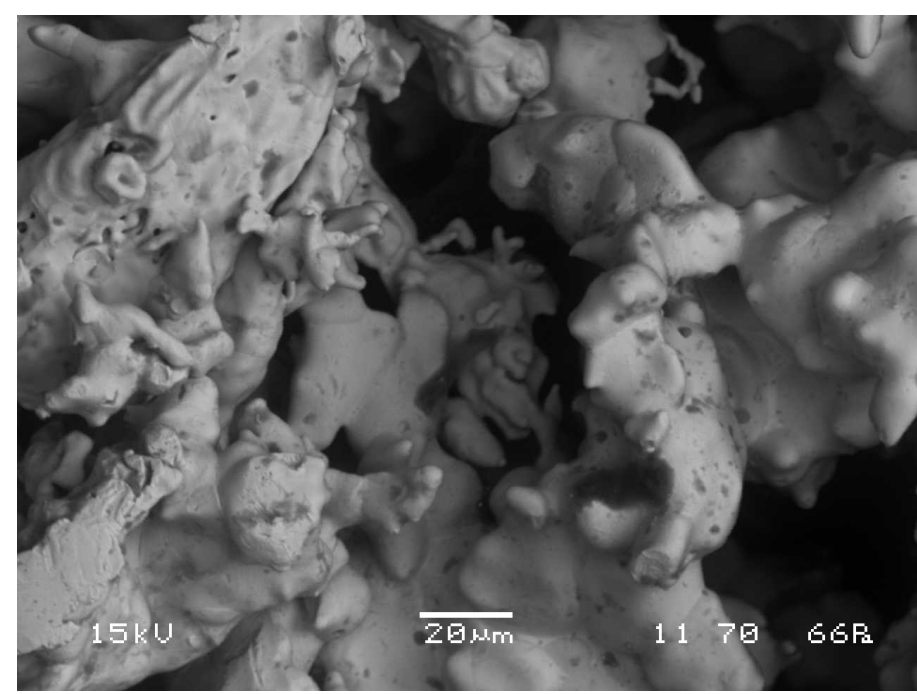

Figure 6. SEM picture of friction material surface. Magnification 650x.

cross section of one test specimen is investigated in an optical microscope, see Fig. 7(a). In this figure it is possible to see that the material between the groove and the steel backing plate is quite dense and that there are much less pores in this area than on the sides of the groove where the material is not much compressed. As told in section 2.2 this groove is $1.5 \mathrm{~mm}$ wide and $0.3 \mathrm{~mm}$ deep.

The groove in Fig. 7(a) can also be compared to a similar cross section, Fig. 7(b), of a groove from a manufactured friction disc, Fig. 1. This groove is slightly less deep compared to the

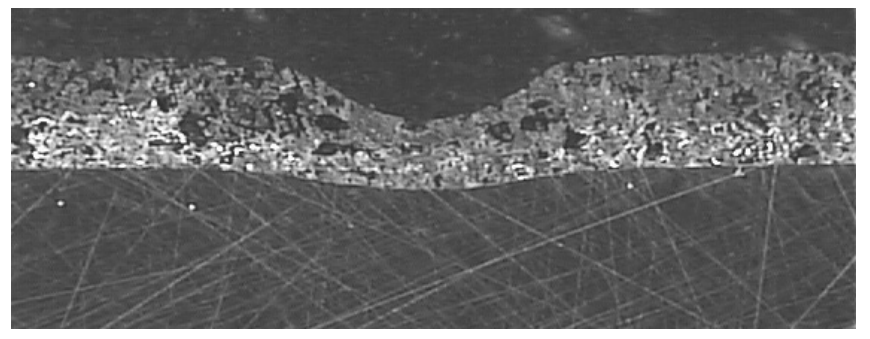

(a) Cross section of groove. Test specimen.

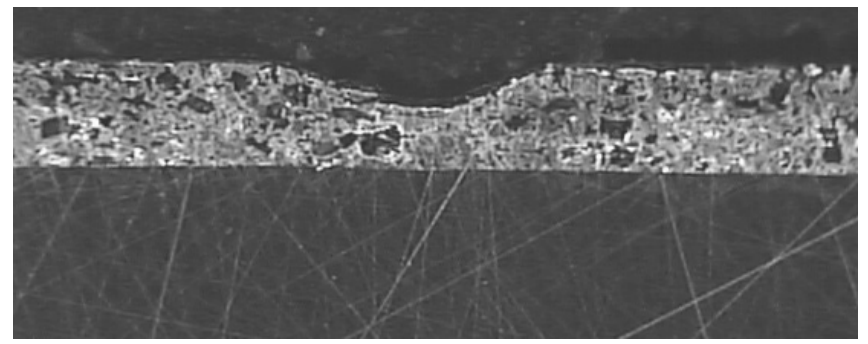

(b) Cross section of groove. Friction disc for a wet clutch.

Figure 7. Cross sections of test specimen and manufactured friction disc for a wet clutch analyzed in an optical microscope.

grooves used in this investigation. However, the steel backing plate is of a steel with much higher strength than the one used for the manufacturing of the test specimens. This is why the steel backing plate in Fig. 7(b) is virtually undeformed under the groove. The thickness of the material between the groove and the steel backing plate could therefore be regarded as quite similar to the thickness of the pressed groove material in the test specimen. It is also obvious that the material is quite dense in this friction lining too which would indicate a very low permeability for the friction material on this disc.

\subsection{Fluid}

The fluid used is water which is held in an absolute pressure of about $10^{4} \mathrm{~Pa}$ for several hours to make sure that solved gases are separated from the water. Water is used because it is a convenient fluid to work with, it has well known properties and quite low viscosity. The low viscosity means that the flow rate for a certain pressure gradient will be larger than for a more viscous flow, like an oil flow, meaning a more exact measurement.

\subsection{Measurements}

In all tests, the measurements are made in a random order. The time of measurement is between 1 and 10 minutes for a non grooved specimen and up to 30 minutes for a grooved specimen. Each test is stopped when a steady state flow is observed. The measured mass flow will reach steady state when there is no air present in the pores of the specimen and all the pipes leading to the balances are filled with fluid. For a material with high permeability the flow will often reach the steady state faster, hence give a shorter necessary time of measurement. The permeability values showed in section 3 are the mean permeability values during the steady state part of the measurement. The temperature in test specimen, test rig and fluid is kept at ambient condition throughout the test.

Measurements are made in a random order and the time of measurement is between 1 and 10 minutes for each test. The measured value of permeability, $K$, is for a steady state flow in the porous media. Two measurements are made for each test specimen in combination with each investigated counter surface.

\subsection{Permeability model}

The flow in the permeable material is governed by the one dimensional form of Darcy's law [12]

$$
\frac{\dot{V}}{A_{c s}}=-\frac{\partial p}{\partial x} \frac{K}{\eta}
$$

Here $\dot{V}$ is the volumetric flow in the direction of the flow, $x, A_{c s}$ is the cross section area of the permeable friction material, $p$ is the pressure, $\eta$ is the fluid viscosity and $K$ is the permeability factor. If the pressure gradient is assumed to be constant through the whole specimen, the equation can be written in the form

$$
K=\frac{\dot{V} \eta w_{f}}{A_{c s} \Delta p}
$$

[6], where $w_{f}$ is the length of the specimen in the flow direction and $\Delta p=p_{\text {inlet }}-p_{a m b}$. The fluid viscosity, $\eta$, is easily calculated from the measured inlet temperature using a temperatureviscosity relationship. The mass flow is measured, implying that 
the volumetric flow can be obtained if the density of the fluid is known. The temperature-density relationship of the fluid is used in order to estimate fluid density. This gives us the final expression:

$$
K=\frac{\dot{m} \eta w_{f}}{A_{c s} \rho\left(p_{\text {inlet }}-p_{a m b}\right)},
$$

where $\rho$ is the fluid density and $\dot{m}$ is the measured mass flow.

For the fluid flow to be governed by Darcy's law the fluid should be Newtonian and incompressible and the Reynolds number should be much less than 1 . For reliable input data it is also important that the viscosity of the measured fluid is fairly constant during the measurements.

If two permeable materials are placed in layers like in Fig. 8 the total cross section area is the sum of the cross section areas

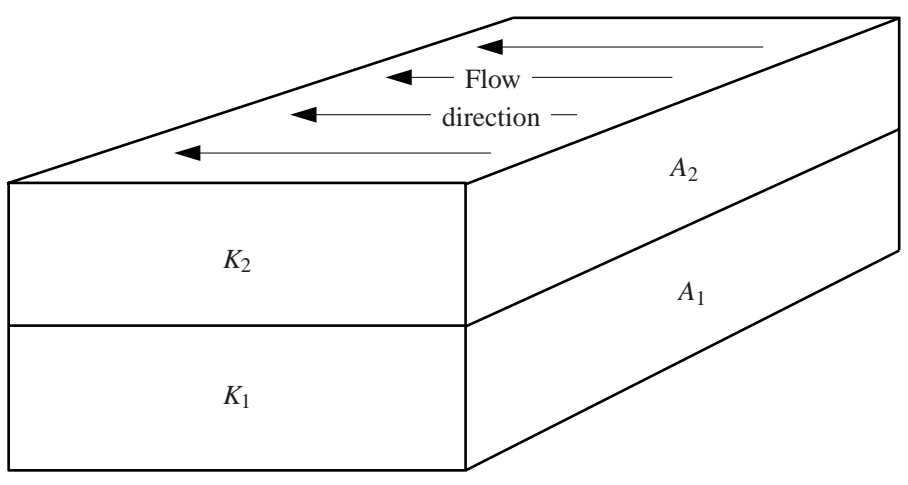

Figure 8. Interaction between two permeable layers.

of the two samples as

$$
A_{\text {tot }}=A_{1}+A_{2} \text {. }
$$

Then the total permeability, $K_{t o t}$, of both layers could be described with

$$
K_{t o t} \cdot A_{t o t}=K_{1} \cdot A_{1}+K_{2} \cdot A_{2} .
$$

If the permeability of layer $2, K_{2}$, is of interest and $K_{t o t}$ and $K_{1}$ is measured, $K_{2}$ can easily be solved as

$$
K_{2}=\frac{K_{t o t} \cdot A_{t o t}-K_{1} \cdot A_{1}}{A_{2}}
$$

\section{RESULTS AND DISCUSSION}

The results are divided into two parts:

The first part, in section 3.1, is an investigation of the permeability of the bulk material and in surface top layer. To see how large the flow can be in the bulk material, first the surface of the test specimens are sealed so that no fluid can flow on top of the specimen. This is then compared to measurements where the seal is replaced with a steel counter surface. This measurement corresponds well to the case in a real wet clutch application. Many pores are open and connected with each other in the interface between the friction material and steel separator disc and a great deal of the liquid can flow through this surface porosity. The difference between these two cases show the distribution between bulk and surface flows.

The second part, in section 3.2, is focused on the influence from the groove patterns on the bulk permeability of the friction material.

\subsection{Bulk flow versus surface flow for friction material with- out grooves}

The permeability value, $K$, is investigated for test specimens with different density and porosity according to Table 1. All specimens are tested with a sealed top surface and a steel counter surface to be able to measure the permeability of the bulk material as well as the permeability of the surface layer.

Figure 9(a) shows the measurement made with a sealed surface. The value of $K$ is obviously dependent of the density of the friction material since $K$ is varying between roughly $2.5 \cdot 10^{-13}$ $\mathrm{m}^{2}$ for a high density specimen and $10 \cdot 10^{-13} \mathrm{~m}^{2}$ for a low density one. The permeability of the friction material with normal density is about $5 \cdot 10^{-13} \mathrm{~m}^{2}$, see Fig. 9(a). From Fig. 9(a) it is also obvious that the variation between different measurements is fairly small.

This bulk permeability of the friction material is often used to describe the permeability properties of a friction material for wet clutch friction discs. However, in a real application the friction material is normally in contact with the relatively smooth surface of the steel separator disc. Because of the rough surface of the friction material there will be a percolating flow in the interface layer between the friction material and steel separator disc. Hence the total permeability of interest in such a wet clutch application is the total permeability computed on the total bulk flow and surface flow. This total permeability is shown in Fig. 9(b). The total permeability in Fig. 9(b) is between $30-75 \%$ higher than the bulk permeability in Fig 9(a). This indicates the importance of measuring the permeability of a complete system insted of just the bulk properties, if the permeability is going to be used to estimate the total porous flow in an application such as a clutch or a porous bearing.

The permeability in the surface layer can be computed with Eq. (6) if the thickness of the permeable interface layer is known. If $50 \%$ of the height from the Abbot-Firestone bearing ratio curve is regarded as the thickness of the permeable surface layer the permeable surface thickness is roughly $60 \mu \mathrm{m}$ for the sintered friction material in this investigation. This gives the surface permeability shown in Fig. 10. This could be used as a permeability value for the surface if it is of interest to separate the bulk flow from the interface flow and that is a more correct way of treating the bulk and surface flow. However in many simulations when the flow in the porous media is of interest, e.g. cooling oil flow in temperature simulations for wet clutches, the combined permeability in Fig. 9(b) can give a easy and enough accurate description of the flow.

The permeability measured in this investigation can be com- 


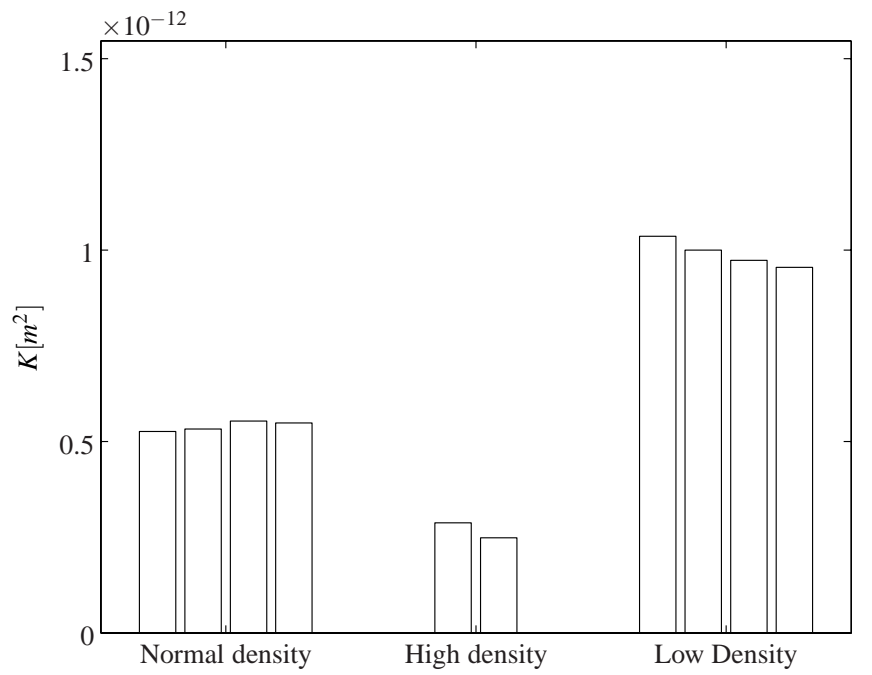

(a) Sealed

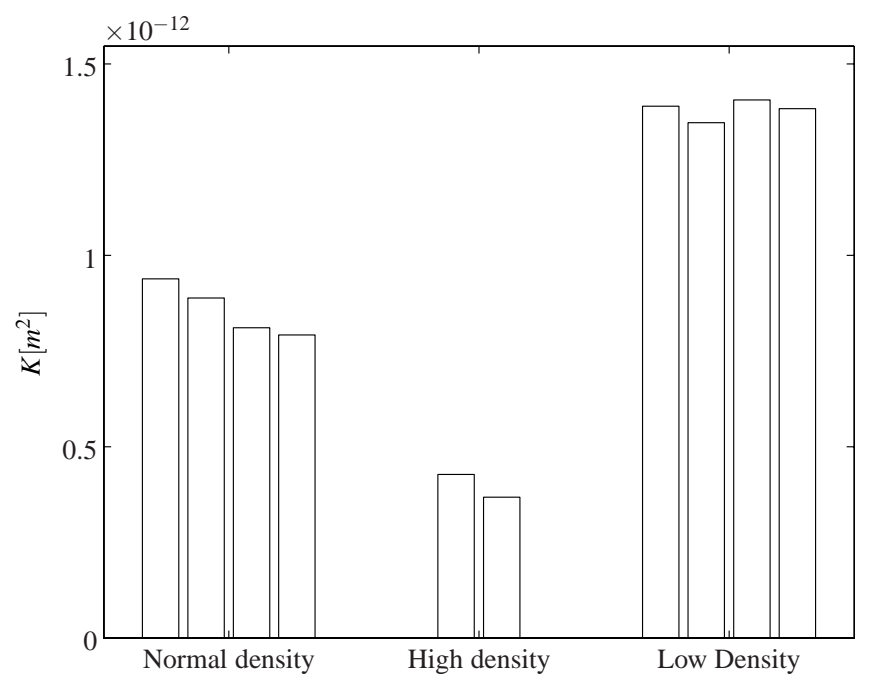

(b) Steel counter surface

Figure 9. Permeability for different density of friction material. Values for sealed test specimen and test specimen with a steel plate counter surface

pared to the permeability used in simulations earlier. One common value of the permeability $[1,3]$ in a friction material for wet clutches is $1 \cdot 10^{-13} \mathrm{~m}^{2}$. This value is smaller than the results showed in Fig. 9. However, the materials in $[1,3]$ are paper based, and the permeability could therefore be different compared to the measured permeability in Fig. 9.

\subsection{Friction material with and without grooves}

The results from section 3.1 show the permeability in the bulk material as well as in the surface layer. To get an idea of how the bulk permeability alters when the friction lining is covered with a pressed groove pattern, like in Fig. 1, the permeability is investigated for test specimens with a pressed groove pattern according to the description in section 2.2. The groove pattern is built up by grooves that are perpendicular to the flow direction, Fig. 3(a). The bulk permeability is measured before and after the groove pattern is pressed which gives an indication of how a groove pattern can change the overall permeability of a

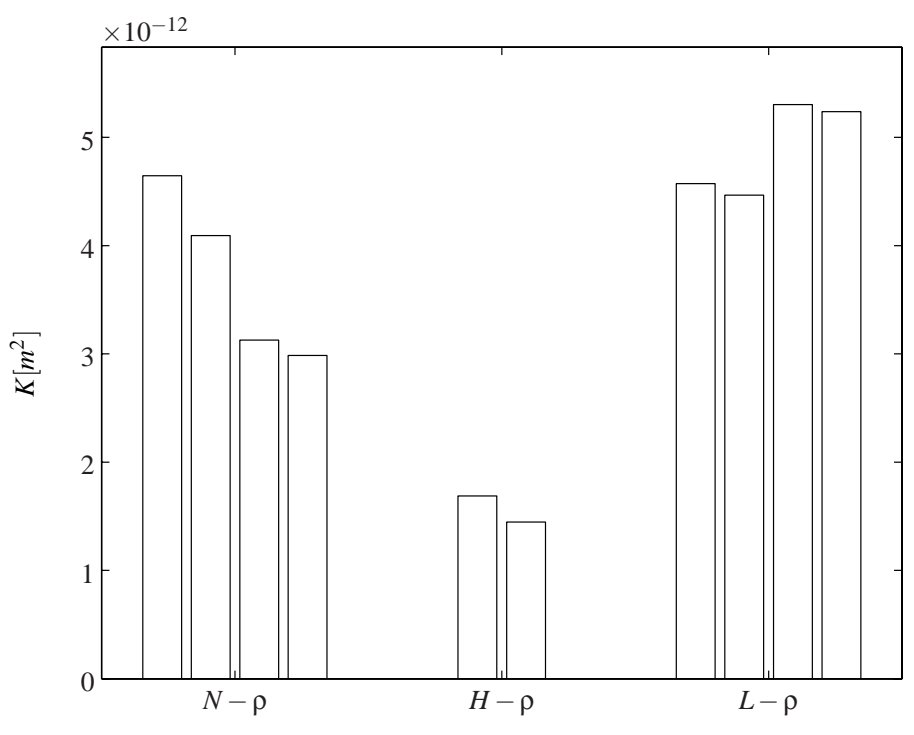

Figure 10. Permeability of porous interface layer.

friction lining on a friction disc. Test specimens with three different densities are used and results from the measurements are shown in Fig. 11 where the three test specimens are marked in Fig. 11 as 1,2 and 3 . The permeability for grooved test specimens are the black bars.

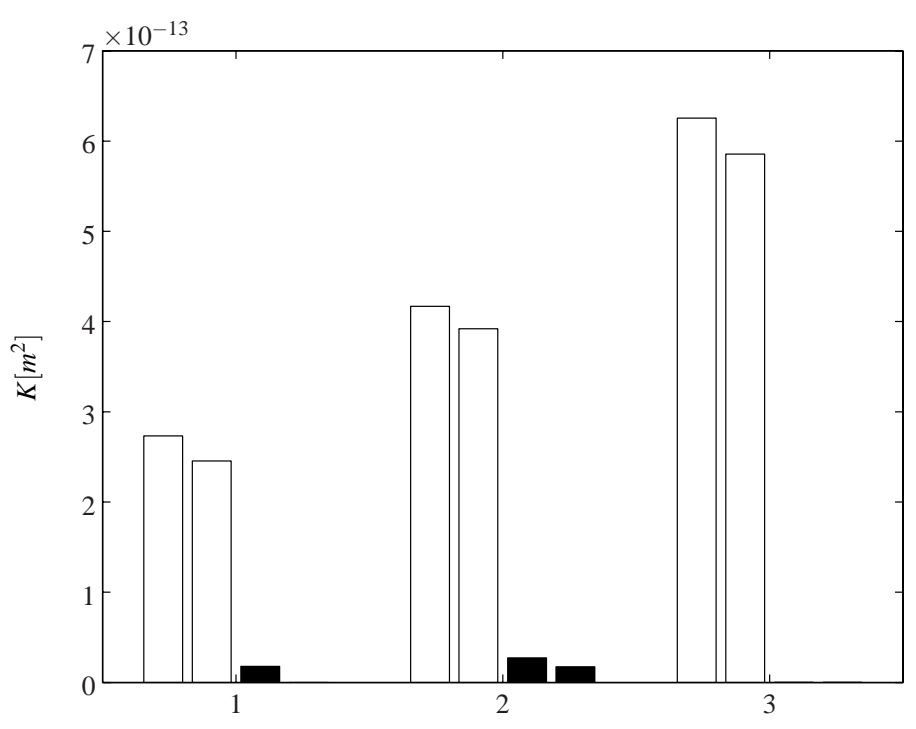

Figure 11. Permeability for different densities before and after groove pattern is pressed into the friction material. Test specimens with groove patterns are marked with black.

The permeability, $K$, is greatly influenced by the pressed groove patterns and $K$ is reduced by an order of magnitude in all measurements. In one of the measurements, test specimen 3 , the specimen became totally impermeable after the groove pattern was pressed. These results indicates that pressed groove pattern in sintered wet clutch friction materials can make the friction material impermeable even if the originally sintered structure is permeable. 


\section{CONCLUSIONS}

The test rig used in this investigation is suitable to measure permeability in wet clutch friction materials. Normal thickness and density of the friction material can be used in the measurements. This is important to get a correct permeability value that is possible to use in simulations and comparisons with other materials.

Different types of friction materials can easily be investigated since the geometry of the measured test specimens is suitable to measure the permeability of thin layers of wet clutch friction materials.

The measured permeability of a sintered bronze friction material differs somewhat from permeability values of paper based materials in other publications.

For a sintered friction material the permeability is much influenced by the density of the friction lining.

Since the friction material most often is in contact with a relatively smooth separator disc in the wet clutch, it is important to measure the permeability under similar conditions. The permeability in the surface interface is of the same order of magnitude as the permeability in the bulk friction material.

When groove patterns are pressed into a sintered friction material the permeability is much decreased. This means that the total permeability could be quite low even if the measured bulk permeability for the material in the friction lining without groove pattern is relatively large.

When comparing permeabilities for different types of friction discs, e.g. different materials, densities, surface roughness and groove patterns, it is of great importance to investigate the permeability for the specific friction material that is of interest. All mentioned parameters influence the porous flow, so it is hard to predict the permeability from other measurements if not the specific combination of parameters is investigated before.

From this investigation it is also concluded that the permeability of the friction material is so small that the possible cooling oil flow in the permeable material, with the pressures present in a wet clutch, probably will be insignificant.

\section{ACKNOWLEDGEMENTS}

The authors would like to thank the colleagues at Haldex Traction Systems, Statoil Lubricants and Luleå University of Technology for their contributions to this work. The SEM investigation is made together with Mr Jens Hardell and his help is very appreciated. Thanks also to the Program Board for Automotive Research (PFF) and the Swedish Foundation for Strategic Research (ProViking) for financial support.

\section{REFERENCES}

[1] Berger, E. J., Sadeghi, F., and Krousgrill, C. M., 1996. "Finite element modeling of engagement of rough and grooved wet clutches". Journal of Tribology, 118, pp. 137 - 146.

[2] Berger, E. J., Sadeghi, F., and Krousgrill, C. M., 1997. "Torque transmission characteristics of automatic transmission wet clutches: Experimental results and numerical comparison". Tribology Transactions, 40(4), pp. 539 - 548.
[3] Jang, J. Y., and Khonsari, M. M., 1999. "Thermal characteristics of a wet clutch". Journal of Tribology, Transactions of the ASME, 121(3), pp. 610 - 617.

[4] Natsumeda, S., and Miyoshi, T., 1994. "Numerical simulation of engagement of paper based wet clutch facing". Journal of Tribology, Transactions of the ASME, 116(2), pp. $232-237$.

[5] Bear, J., 1972. Dynamics of fluids in porous media. Dover Publications Inc.

[6] Lundstrom, T. S., Toll, S., and Hakanson, J. M., 2002. "Measurement of the permeability tensor of compressed fibre beds". Transport in Porous Media, 47(3), pp. 363 380.

[7] Ahn, S. H., Lee, W. I., and Springer, G. S., 1995. "Measurement of the three-dimensional permeability of fiber preforms using embedded fiber optic sensors". Journal of Composite Materials, 29(6), pp. 714 - 733.

[8] Gebart, B. R., and Lidström, P., 1996. "Measurement of in-plane permeability of anisotropic fiber reinforcements". Polymer Composites, 17(1), pp. 43 - 51.

[9] Lindsay, J. D., 1990. "The anisotropic permeability of paper”. Tappi Journal, pp. 223 - 229.

[10] Chavdar, B., 2002. "A permeameter measuring normal and lateral permeability and an investigation on wet friction materials". International SAMPE Symposium and Exhibition (Proceedings), 47 I, pp. $253-266$.

[11] Beavers, G. S., and Joseph, D. D., 1967. "Boundary conditions at a naturally permeable wall". Journal of fluid mechanics, 30, pp. $197-207$.

[12] Cameron, A., 1976. Basic lubrication theory, Vol. 2. Chichester. 